\title{
Experience in the management of the true ankylosis of the temporomandibular joint: A suggested protocol for treatment
}

\begin{tabular}{ccc}
\hline Reiadh K. Al-Kamali * & Ali F. Al-Zubaidi * & Hundreen M. Ali * \\
\hline Abstract
\end{tabular}

Background and objective: True ankylosis of the temporomandibular joint may be defined as joint surfaces fusion. It can affect the function adversely and when occurs during childhood, it can adversely affect mandibular growth. The treatment is usually surgical, but, unfortunately, poses a significant challenge because of the high recurrence rate. The objective of this paper is to evaluate the outcome of following a definitive protocol in the treatment of temporomandibular joint ankylosis.

Methods: Seventy-seven patients, 36 unilateral and 41 bilateral ankylosis (118 ankylosed joints) were diagnosed clinically and radiologically as having true ankylosis of the temporomandibular joint during the period between 2001 and 2013. Resection of the ankylosed bone or horizontal ramus osteoctomy of the affected side with interpositional autogenic or alloplastic material, with possible ipsilateral and/or contralateral coronoidectomy to achieve the definitive interincisal opening of not less than $35 \mathrm{~mm}$.

Results: The postoperative measurement of interincisal opening of $\geq 35 \mathrm{~mm}$ with lateral and protrusive movement was the criteria for success of surgery. Reankylosis occurred in 7 unilateral and 12 bilateral cases.

Conclusion: Postoperative jaw opening exercises are crucial for lasting success and failure of patient compliance is the cause of reankylosis.

Keywords: temporomandibular joint, ankylosis, gap arthroplasty, horizontal ramus osteoctomy, coronoidectomy.

\section{Introduction}

The normal mouth opening that would allow for normal functions has been estimated to be $35-40 \mathrm{~mm}$ in the adult. This opening allows for normal functions and maintenance of oral hygiene including the introduction of the dental hand piece and other dental instruments for dental treatment. $^{1}$ The temporomandibular joint (TMJ) ankylosis can affects the TMJ as well as the surrounding structures. It is classified into intra-articular and extra-articular ankylosis. ${ }^{2}$ It can be bony, fibrous, fibroosseous, complete and incomplete., ${ }^{3,4}$ The main causes of the TMJ ankylosis are the trauma (with disruption of the meniscus and organization of haematoma within the joint with or without a related intracapsular fracture of the condyle), and infection (otitis media or mastoiditis). The other etiologic factors are rheumatoid arthritis, ankylosing spondylitis, and burns. ${ }^{5}$ In unilateral cases there is facial asymmetry with the chin deviates toward the affected side. Recession of the chin, on the other hand, is a typical characteristic of the bilateral ankylosis. ${ }^{4}$ Dental crowding and malalignment and poor oral hygiene can often be observed in both unilateral and bilateral cases. The main principles of treatment are: (a) satisfactory resection of the ankylosing bone (gap arthroplasty); (b) use of interpositional material, if it is needed; and (c) early aggressive postoperative physiotheraphy. ${ }^{6-9}$ The gap arthroplasty, when used alone, is still preferred by some,${ }^{10}$ but the gap arthroplasty with the placement of interpositional material is considered the standard procedure by

* Department of oral \& maxillofacial surgery, college of dentistry, Hawler medical university, Erbil, Iraq. 
http://dx.doi.org/10.15218/zjms.2015.0009

others. ${ }^{11-13} \mathrm{~A}$ range of materials is used for interpositional surgery including temporalis fascia, temporalis muscle, cartilage grafts, silastic materials, etc. ${ }^{7,14-18}$. Recently, distraction osteogenesis has become a popular method for correction of the mandibular deformity and relief of upper airway obstruction due to ankylosis. ${ }^{19} \mathrm{Up}$ till now, there has been no single method could produce a uniformly successful results with no postoperative limitation of jaw opening and recurrence of ankylosis. ${ }^{20}$ Early postoperative jaw mobilization and aggressive physiotherapy are an integral part of a treatment protocol for TMJ ankylosis. ${ }^{21}$ The purpose of this paper is to demonstrate the experience gained by the authors from the management of 77 patients (118 joints) in order to standardize the management of this relatively common problem.

\section{Methods}

Seventy-seven patients (118 ankylosed joints) with true ankylosis of the TMJ were treated surgically in different hospitals in Baghdad and Erbil during the period 2001-2013. The patient is diagnosed having true ankylosis of the TMJ when his maximal jaw opening is less than $35 \mathrm{~mm}$ and the radiographic views demonstrate the ankylosis within the joint. Accordingly, 36 of these patients were diagnosed with unilateral ankylosis and the other 41 patients were with bilateral ankylosis. All of those patients had been radiographed for an OPG view to have an idea about the size of the ankylosis. They also been CT scanned to identify the exact size and the amount of the medial extension of the ankylosis and its relation to the carotid and jugular foramina. Attention had also been paid to presence of elongated coronoid process from its absence. In the majority of these patients the general anaesthesia was maintained through a tracheostomy. For the unilateral cases, the ankylosis was approached through the extended preauricular incision and treated by the creation of gap arthroplasty above the mandibular foramen. In those cases where the jaw opening could not be increased after the gap arthroplasty undertaken, the ipsilateral coronoid process were excised. If, in spite of that, the jaw opening was still restricted, the contralateral coronoid process of the mandible was removed. The lower jaw could then be manipulated to $4 \mathrm{~cm}$ interincisal opening and the gap arthroplasty was considered complete only when there is $1.5 \mathrm{~cm}$ between the skull base and the mandibular stump at this opening. For the complying patient, the wound is closed at this stage. Should there is a question about patients compliance with the postoperative physiotherapy, the gap arthroplasty is managed either by the introduction of a sialastic block or the temporalis muscle flap into the gap arthroplasty before closure of the wound. In the unilateral cases with the ankylosis approximating the jugular foramen, as indicated by the CT scan, a horizontal ostectomty were created in the ramus just above the mandibular angle to effect the intraoperative $4 \mathrm{~cm}$ interincisal opening. The inferior dental neurovascular bundle is preserved and the space obliterated by stitching the medial pterygoid muscle to the masseter muscle (Figure 1). In these cases the ramus of the mandible is approached through the Zide and Epker's modification of the submandibular approach. ${ }^{22}$ In this modification, the skin incision is put $1 \mathrm{~cm}$ below the inferior border of the mandible to have more extensile approach to the ramus of the mandible.

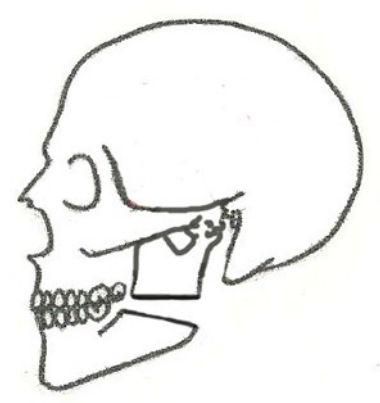

Figure 1: The horizontal ostectomy above the mandibular angle 
http://dx.doi.org/10.15218/zjms.2015.0009

For the bilateral cases, the ankylosis was treated by the creation of gap arthroplasty above the mandibular foramen on both sides. That was followed by the use of the temporalis muscle flaps to line up the bed of the gap arthroplasty on both sides. In those cases where the gap arthroplasty approached $3 \mathrm{~cm}$, a costal graft or a sialastic block (in the adult) or a costochondral grafts (in the child) were used to restore the ramal height on both sides. This is carried out through the combined preauricular and submandibular approaches. All bone cuts have been done with the bur after adequate exposure of the anterior and posterior borders of the ramus and the sigmoid notch. In depth cutting of the bone was only performed after wide removal of the more superficial bone and gradual subperiosteal advancement of a periosteal elevator along the medial side of the condylar stump in a foreword direction. We have never hammer a chisel or an osteotome to remove the ankylosed bone at any stage of the operation. In the event of abnormal bleeding during removal of the deep ankylosed bone, the gap arthroplasty is completed quick, even at a lower level, so that packing the gap by gauze would be affective to control the bleeding. Active jaw exercises are started immediately after the postoperative pain and swelling subsided or the IMF, when used, is released. The wooden tongue blades were used to increase the jaw opening back to what have been gained during the surgery. The patient is seen regularly each week during the first month for checking the jaw opening. Afterward, the patient is seen on three months base for one year.

\section{Results}

The surgical techniques that have been used in the treatment of the unilateral cases of TMJ ankylosis are shown in Table 1. No one of the six patients who were treated by osteoectomy at the mandibular angle needed coronoidectomy to achieve the functional jaw opening. All but one of the other 30 unilateral cases of ankylosis

has had coronoidectomy to achieve the functional jaw opening (Table 2). The surgical techniques used for the treatment of bilateral cases of ankylosis are shown in Table 3.

Table 1: Surgical treatment of unilateral ankylosis.

\begin{tabular}{lll}
\hline Surgery & No. & $\%$ \\
\hline $\begin{array}{l}\text { 1.Gap arthroplasty above the } \\
\text { mandibular foramen }\end{array}$ & 8 & 22.22 \\
$\begin{array}{l}\text { 2. Gap arthroplasty above the } \\
\text { mandibular foramen + Placement } \\
\text { of interpositional material: } \\
\quad \text { Sialastic block }\end{array}$ & 5 & 13.88 \\
$\quad$ Temporalis muscle flap & 6 & 16.66 \\
$\begin{array}{l}\text { 3. Horizontal ostectomy at the } \\
\text { mandibular angle }\end{array}$ & & \\
Total & 36 & 100 \\
\hline
\end{tabular}

Table 2: Coronoidectomy in the unilateral ankylosis surgery.

\begin{tabular}{lll}
\hline Coronoidectomy & No. & \%(no=36) \\
\hline Ipsilateral coronoidectomy & 18 & 50.00 \\
Ipsilateral + Contralateral & 11 & 30.55 \\
$\begin{array}{l}\text { coronoidectomy } \\
\text { Total }\end{array}$ & 29 & 80.55 \\
\hline
\end{tabular}

Table 3: Surgical treatment of bilateral ankylosis.

\begin{tabular}{lll}
\hline Surgery & No. & $\begin{array}{l}\text { \% } \\
\text { (no=41) }\end{array}$ \\
\hline $\begin{array}{l}\text { 1. Gap arthroplasty above the } \\
\text { mandibular foramen: } \\
\quad \begin{array}{l}\text { Gap arthroplasty + Temporalis } \\
\text { muscle flaps }\end{array}\end{array}$ & 8 & 19.51 \\
$\begin{array}{l}\text { Gap arthroplasty + Temporalis } \\
\text { muscle flaps + costal grafts } \\
\text { Gap arthroplasty + Temporalis } \\
\text { muscle flaps + costochondral } \\
\text { grafts }\end{array}$ & 4 & 9.75 \\
$\begin{array}{l}\text { 2. Bilateral horizontal ostectomy at } \\
\text { the mandibular angle }\end{array}$ & 6 & 43.90 \\
$\begin{array}{l}\text { 3. Gap arthroplasty above the } \\
\text { mandibular angle at one side + }\end{array}$ & 5 & 14.63 \\
$\begin{array}{l}\text { Horizontal ostectomy at the } \\
\text { mandibular angle in the other side }\end{array}$ & & \\
\begin{tabular}{l} 
Total \\
\hline
\end{tabular} & 41 & 100 \\
\hline
\end{tabular}


http://dx.doi.org/10.15218/zjms.2015.0009

No one of the 6 patients treated by bilateral horizontal ostectomies at the mandibular angle needed coronoidectomy to achieve the required functional mouth opening. Table 4 is, therefore, demonstrating the coronoidectomies among the other 35 bilateral cases. Seven out of the 36 unilateral cases and 12 out of the 41 bilateral cases had reankylosis (Tables 5 and 6).

Table 4: Coronoidectomy in bilateral cases.

\begin{tabular}{lll}
\hline Coronoidectomy & No. & \%(no=41) \\
\hline Coronoidectomy on one side & 8 & 19.51 \\
Coronoidectomy on both sides & 22 & 53.65 \\
Total & 30 & 73.17
\end{tabular}

Table 5: Reankylosis in the unilateral cases.

\begin{tabular}{lll}
\hline Surgery & No. Reankylosis & (\%) Reankylosis (no=36) \\
\hline $\begin{array}{l}\text { 1. Gap arthroplasty above the mandibular foramen } \\
\text { Sialastic block }\end{array}$ & 2 & 5.55 \\
$\begin{array}{l}\text { 2. Gap arthroplasty above the mandibular foramen + Placement } \\
\text { of interpositional material: }\end{array}$ & 1 & 2.77 \\
& 3 & 8.33 \\
3. Horizontal ostectomy at the mandibular angle & 1 & 2.77 \\
Total & 7 & 22.22
\end{tabular}

Table 6: Reankylosis in the bilateral cases

\begin{tabular}{lll}
\hline Surgery & $\begin{array}{l}\text { No. } \\
\text { Reankylosis }\end{array}$ & $\begin{array}{c}\text { \% Reankylosis } \\
\text { (no=41) }\end{array}$ \\
\hline $\begin{array}{l}\text { 1. Gap arthroplasty above the mandibular foramen: } \\
\text { Gap arthroplasty + Temporalis muscle flaps }\end{array}$ & 2 & 4.87 \\
$\begin{array}{l}\text { Gap arthroplasty + Temporalis muscle flaps + costal grafts } \\
\text { Gap arthroplasty + Temporalis muscle flaps + costochondral grafts }\end{array}$ & 0.00 & 0.00 \\
& 6 & 14.36 \\
2. Bilateral horizontal ostectomy at the mandibular angle & 2 & 4.87 \\
\hline $\begin{array}{l}\text { 3. Gap arthroplasty above the mandibular angle at one side + Horizontal } \\
\text { ostectomy at the mandibular angle in the other side }\end{array}$ & 2 & 4.87 \\
Total & & 28.87 \\
\hline
\end{tabular}


Neural deficits: The majority of the gap arthroplasty above the mandibular foramen (65 patients) had temporary weakness in the frontal branch of the facial nerve. This weakness lasted for the average of three weeks to resolve spontaneously. All of the patients who had horizontal osteoectomy the mandibular angle (17 patients) had numbness in the lower lip and six of them kept permanent paraesthesia (Table 7). Skeletal malrelation: Table 8 shows the skeletal malrelationships caused by removal of the ankylosis

\section{Discussion}

The ankylosis can results in a narrow oropharyngeal airway secondary to shortening of mandibular rami and narrowing of space between the mandibular angles. This, in turn, when combined with restricted jaw opening may results in difficulty with intubation of the patient. Awake nasal intubation is the safest approach of intubation. Nasal intubation, either blind or fiberoptic guided, and a tracheostomy are the different techniques of securing airway in these patients. ${ }^{23}$ The authors were unfortunate to work in centres with inadequate facilities for blind or fiberoptic guided nasal intubation. This fact explains the need for tracheostomy in the majority of their patients Reankylosis is an ever-present problem and can happen irrespective of the technique chosen by the surgeon. After gap arthroplasty, the chance of reankylosis is greater when there is shortening of the ramus or lack of postoperative exercises. ${ }^{24}$ Although some authors claim that the gap arthroplasty, when used as the sole treatment for ankylosis, does not usually results in successful treatment, ${ }^{25}$ others found no recurrencein their series with a follow up of at least 24 months. ${ }^{26}$ The present authors agree with the latter treatment but only when they prospectively trust the patient compliance with the required postoperative exercises. They adopted this surgery in the management of 8 patients with unilateral ankylosis in whom no excessive shortage in the ramus has resulted after removal of the ankylosis.

Table 7: Neural deficits.

\begin{tabular}{lllll}
\hline Nerve Deficit & $\begin{array}{l}\text { Temporary } \\
\text { deficit } \\
\text { No. }\end{array}$ & $\begin{array}{l}\text { Temporary } \\
\text { deficit } \\
\%\end{array}$ & $\begin{array}{l}\text { Permanent } \\
\text { deficit } \\
\text { No. }\end{array}$ & $\begin{array}{l}\text { Permanent } \\
\text { deficit } \\
\%\end{array}$ \\
\hline $\begin{array}{l}\text { Weakness of the frontal branch of the facial nerve } \\
\text { Neakness of the mandibular branch of the facial }\end{array}$ & 62 & $\begin{array}{l}95.38 \\
(\mathrm{no}=65)\end{array}$ & 3 & $\begin{array}{l}4.61 \\
(\mathrm{no}=65)\end{array}$ \\
$\begin{array}{l}\text { Werve } \\
\text { numbness in the lower lip }\end{array}$ & 8 & $\begin{array}{l}20.51 \\
(\mathrm{no}=39)\end{array}$ & 1 & $\begin{array}{l}2.56 \\
(\mathrm{no}=39)\end{array}$ \\
& 17 & $\begin{array}{l}100 \\
(\mathrm{no}=17)\end{array}$ & 6 & $\begin{array}{l}35.29 \\
(\mathrm{no}=17)\end{array}$ \\
\hline
\end{tabular}

Table 8: Skeletal and dental malrelation.

\begin{tabular}{lll}
\hline Skeletal malrelation & No. & $\%$ \\
\hline Anterior open bite after surgery for bilateral ankylosis & 7 & $\begin{array}{l}17.07 \\
(\mathrm{no}=41) \\
13.88\end{array}$ \\
Cross bite after surgery for unilateral ankylosis & 5 & $(\mathrm{no}=36)$ \\
\hline
\end{tabular}


http://dx.doi.org/10.15218/zjms.2015.0009

However, the authors did not use this kind of treatment for the treatment of bilateral ankylosis even though the gap arthoplasties did not excessively shorten the mandibular rami. This is because of the increased chance of reankylosis in these cases, and, in turn, the temporalis muscle flap has been used in such cases to reduce this chance happening. Placement of interpositional material at the gap arthroplasty is a mechanism for restoring the ramal height and thus helps in preventing recurrence. ${ }^{25-28}$ The authors practice is to place an interpositional material whenever complete removal of the ankylosis ended with more than $3 \mathrm{~cm}$ gap between the skull base and mandibular stump. They used the sialastic block in five patients, the costal graft in 4 patients, and the costochondral graft in 18 patients with successful results. However, the authors also believe that in the treatment of bilateral cases of ankylosis the temporalis muscle flaps must be used with the aforementioned interpositional materials as reankylosis could occur when these materials are used alone. ${ }^{29}$ The most widely accepted technique in children is the costochondral graft use. ${ }^{27,28}$ This is obviously because of its growth potential and functional adaptability. ${ }^{28}$ The authors practice is to use the temporalis muscle flap to cover the skull base and the gap arthroplasty so that the graft with its cartilaginous head is settled on the muscle rather on the bone. The authors had modified the temporalis muscle flap so that its posterior third is reflected to cover up the bed of the gap arthroplasty and line the medial side of the mandibular ramus. ${ }^{21}$ The authors also use this kind of flap when the costal graft has been used as an interpositional material. It is well known that the coronoid process tends to grow in a long-standing ankylosis causing inadequate intraoperative interincisalopening. ${ }^{26}$ Hence, 59 of the patients in this study underwent coronoidectomy to reach a functional jaw opening. It is the author's observation that the temporalis muscle, in some of these patients, is so stiff that it is limiting the jaw opening even though the coronoid process looks normal in the $x$-ray films. Coronoidectomy is needed in these situations to affect a functional jaw opening. Ninteen out of the 77 patients $(24.67 \%)$ in this study had reankylosis, and the authors attribute this apparantly high percentage to their strict definition of the reankylosis and to the lack of patient compliance with the required postoperative exercises. These patients stop the exercises early in postoperative period because of the pain they feel or their ignorance of the importance of these exercises in the prevention of reankylosis. Furthermore, in order to reduce the chance of reankylosis to the minimum possible, the authors practice is to make sure that the interincisal opening is at least $40 \mathrm{~mm}$ after the creation of a gap arthroplasty of $1.5 \mathrm{~cm}$ at this opening. They also use the modified temporalis muscle flap whenever an interpositional material has been used to restore the remal height. ${ }^{21}$ The surgical approach used to gain access to the area of the ankylosis places the facial nerve at risk for damage. ${ }^{30} \mathrm{~A}$ loss of function of the frontalis and orbicularis oculi muscles is always a possibility ${ }^{30}$, but it is usually temporary and resolve spontaneously after few weeks. The incidence of permanent damage to the frontal branch of the facial nerve in this study was $4.5 \%$ as it is the authors practice is to extend the temporal extension of the preauricular incision almost to the vertical tangent of the lateral canthus of the eye and to keep the dissection to the ankylosis deep to the temporal fascia. In this study, the incidence of permanent numbness in the lower lip among those underwent horizontal ostectomy at the mandibular angle is high. This is because, in the event of nerve cut, no attempt had been taken at immediate repair of the inferior dental nerve after the ostectomy.

\section{Conclusion}

Successful treatment of TMJ ankylosis 
http://dx.doi.org/10.15218/zjms.2015.0009

depends on a number of factors. Resection of the ankylosed bone should be carried out through a wide surgical exposure. This approach would allow for radical removal of the ankylosis with the minimum damage to the branches of the facial nerve. Radical removal of the ankylosed bone is essential for the prevention of reankylosis. The gap arthroplasty, when used alone, is enough as a treatment when the ankylosis is small and its removal does not shorten the ramus more than $1 \mathrm{~cm}$. Restoration of the ramal height after removal of larger ankylosis is essential for the prevention of reankylosis and the creation of anterior open bite. Careful selection of the patients who are expected to comply with postoperative functional rehabilitation is essential to achieve successful treat ment. Regular follow-up for at least 1 year and continuous motivation for adequate jaw exercises are crucial for the success of the treatment.

\section{Conflicts of interest}

The author reports no conflicts of interest.

\section{References}

1. Hamad SA, Al-Kamali, Ali HM. The normal range of mouth opening in Kurdish population and its correlation to age, sex, height and weight. Zanco J Med Sci 2010; 14 (3): 41-6.

2. Kazanjian $\mathrm{VH}$. Ankylosis of temporomandibular joint.Surg Gynaecol Obstet 1938; 67:333-48.

3. Rowe NL. Ankylosis of the temporomandibular joint. J R CollSurgEdinburgh 1982; 26:67-79.

4. Sawhney CP. Bony ankylosis of the temporomandibular joint: follow-up of 70 patients treated with arthroplasty and acrylicspacer interposition. Plast Reconstr Surg 1986; 77:29-38.

5. Nayak PK, Nair SC, Krishnan DG, Perciaccante VJ. Ankylosis of the Temporomandibular Joint. In: Maxillofacial Surgery. $2^{\text {nd }}$ ed. St. Louis, Missouri: Churchill Livingstone; 2007: 1522-37.

6. Martis C, Marti K. Temporomandibular joint ankylosis: the problem of restoration. Hell Period Stomat Gnathopathoprosopike Cheir 1990; 5: 135-40.

7. Kalamchi S, Walker RV. Silastic implant as a part of temporomandibular joint arthroplasty. Evaluation of its efficiacy.Br J Oral MaxillofacSurg 1987; 25: 227-36.

8. Kirk Ws, Farrar JH. Early surgical correction of unilateral TMJ ankylosis and improvement in mandibular symmetry withuse of an orthodontic functional appliance.A case report.Cranio 1993; 11:308-11.
9. Guyot L, Choossegros C, Cheynet F, Gola R, Lachard J, Blanc JL. Clinique de stomatologieetchirurgiemaxillo-faciale. RevStommatolChirMaxillofac 1995; 96:372-8.

10. Devgan A, Siwach RC, Sangwan SS. Functional restoration by excision arthroplasty in temporomandibular joint ankylosis--a report of 35 cases. Indian J Med Sci 2002; 56(2):61-4.

11. Valentini V, Vetrano $S$, Agrillo A, Torroni A, Fabiani $F$, lannetti $G$. Surgical treatment of TMJ ankylosis: our experience (60 cases). J CraniofacSurg 2002; 13(1):59-67.

12. Su-Gwan K. Treatment of temporomandibular joint ankylosis with temporalis muscle and fascia flap. Int J Oral Maxillofac Surg 2001; 30(3): 189-93.

13. Saeed NR, Kent JN. A retrospective study of the costochondral graft in TMJ reconstruction.Int $\mathrm{J}$ Oral Maxillofac Surg 2003; 32(6):606-9.

14. Su-Gwan K. Treatment of temporomandibular joint ankylosis with temporalis muscle and fascia flap. Int J Oral Maxillofac Surg 2001; 30(3): 189-93.

15. Liu G, Li Z, Dong Y. Autogenous costochondral graft applied in the reconstruction of the temporomandibular joint. Zhonghua Zheng Xing WaiKeZaZhi 2000; 16(3):163-5.

16. Demir Z, Velidedeoglu H, Sahin U, Kurtay A, Coskunfirat OK. Preserved costal cartilage homograft application for the treatment of temporomandibular joint ankylosis. Plast Reconstr Surg 2001; 108(1):44-51.

17. Balaji SM. Modified temporalis anchorage in craniomandibular reankylosis. Int J Oral MaxillofacSurg $2003 ; 32(5): 480-5$.

18. Rao K, Kumar S, Kumar V, Singh AK, Bhatnagar SK. The role of simultaneous gap arthroplasty and distraction osteogenesis in the management of temporomandibular joint ankylosis with mandibular deformity in children. $J$ Craniomaxillofac Surg 2004; 32:38-42.

19. Long X, Li X, Cheng Y, Yang X, Qin L, Qiao Y, et al. Preservation of disc for treatment of traumatic temporomandibular joint ankylosis. J Oral Maxillofac Surg 2005; 63(7): 897-902.

20. Kaban LB, Bouchard C, Troulis MJ. A Protocol for Management of Temporomandibular joint Ankylosis in children.J Oral Maxillofac Surg 2009; 1966-78.

21. Al-Kamali RK, Al-Zubaidy AF. Experience with the prevention of reankylosis of the temporomandibular joint. Iraqi Dent J 2002; 31:245-56.

22. Zide M, Epker BN. An alternate elective neck incision. J Oral Maxillofac Surg 1993; 51: 1071.

23. Shah FR, Sharma RK, Hillowall RN, Karandikar AD. Anaesthetic considerations of temporomandibular joint ankylosis with obstructive sleep apnoea : a case report. J Indian Soc Pedo Prev Dentistry 2002; 20(1):16-20.

24. Vasconcelos BC, Bessa-Nogueira RV, Cypriano RV. Treatment of temporomandibular joint 
ankylosis by gap arthroplasty. Med Oral Patol Oral Cir Bucal 2006; 11(1):66-9.

25. Erdem E, Alkan A. The use of acrylic marbles for interposition arthroplastyin the treatment of temporomandibular joint ankylosis: follow-up of 47 cases.Int J Oral Maxillofac Surg 2001; 30(1):32-6.

26. Raveh $\mathrm{J}$ et al: Temporomandibular joint surgical treatment and long term results. J. Oral Maxillofacial Surg 1989; 47: 900-6.

27. Kaban LB, Perrott DH, Fisher K. A protocol for management of Temporomandibular joint ankylosis. J Oral Maxillofac Surg1990; 48 (11):1145-51.

28. Maclntosh RB. The use of autogenous tissues for temporomandibular

joint reconstruction. J Oral Maxillofac Surg 2000; 58 (1):63-9.

29. Schobel G, Millesi W, Watzke IM, Hollmann K. Ankylosis of the Temporomandibular joint. Follow-up of thirteen patients. Oral Surg Oral MedOral Pathol 1992; 74(1):7-14.

30. Politi M, Toro C, Cian R, Costa F, Robiony M. The deep subfascial approach to the temporomandibular joint. J Oral Maxillofac Surg 2004; 62(9):1097-102. 